\title{
A Construção do Gênero no Espaço Escolar
}

Ileana Wenetz Marco Paulo Stigger

Resumo: Procuramos, a partir das vertentes dos Estudos Culturais e de Gênero que se aproximam do pós-estruturalismo de Foucault, entender como o gênero e a sexualidade instituem modos diferenciados de ser menino/a no recreio escolar. Considerando que esse é um processo permeado por relações do poder, procuramos mapeá-las e identificá-las utilizando uma metodologia de inspiração etnográfica (observação participante e entrevistas) realizada, durante um ano, numa escola pública de Porto Alegre, RS. Focalizamos uma segunda e uma terceira série. Argumentamos que, através das brincadeiras, acontece uma aprendizagem não-formal e não-intencional, a partir da qual crianças apre(e)endem determinadas formas de feminilidade e de masculinidade.

Palavras-chave: Estudos de Gênero. Recreio. Etnografia. Brincadeiras.

\section{Apresentação}

Pátio, sol, sirene, dez e quinze, gritos, corre-corre, risadas, quadras, lanche, bebedouro, chutes, salgadinhos, conversa, passeio; funcionário olhando as crianças, camisetas, corda, segredinhos, futebol, mochilas, jogo de mãos, empurra-empurra; uma menina arruma o cabelo, outras duas fofocam, bola para cima e para baixo, ventinho na cara, um menino amarra o cadarço, uma professora atravessa rapidamente o pátio; alunos e alunas sentados nos bancos, passa outra professora, meninos brincam com fichas no chão, filas, descanso, passam duas professoras, muitas vozes juntas que não permitem ouvir ninguém, dois meninos se empurram e um terceiro fica olhando; no canteiro, crianças estão sentadas enquanto outra turma joga basquete na quadra; dois adolescentes passam caminhando, uma menina caminha até a porta, outras duas passam correndo de mãos dadas, uma menina tapa os olhos da colega, deixa-se ver e sai correndo com sua amiga atrás; minissaias, abra-

Movimento, Porto Alegre, v.12, n. 01, p. 59-80, janeiro/abril de 2006. 
ços, celular, boneca, funcionária xingando...

Alguém reconhece esse momento? Esse espaço fez/faz parte do quotidiano de muitos de nós, seja na época em que éramos escolares, seja como profissionais. E, como se pode ver na descrição acima apresentada, ele é, também, um espaço muito rico em relação à complexidade de cores, sons, sinais, ruídos, situações e significados. O recreio é um momento em que se misturam as vozes das crianças com suas risadas e gritos estridentes, com as das professoras e suas advertências e chamadas de ordem. Neste contexto, barulhos misturam-se num som contínuo, mas a sirene, sempre altíssima, repentinamente cala-os todos. É também assim que a escola vai marcando o seu próprio som, seu próprio ritmo, sua regularidade, a hora da entrada e da saída, a hora de fazer fila....

Mas também existem silêncios no recreio, o das vozes que não se ouvem. Quem não fala ou fala e se confunde com as outras falas? Quem resiste a fazer alguma coisa não permitida? Quem desvia? Quem cria?

A possibilidade de refletir hoje sobre essas temáticas corresponde a uma série de questionamentos e inquietudes que o dia-a-dia nos coloca. Expressões quotidianas - de agrado ou desagrado - vindas das crianças e relacionadas a determinadas atividades parecem ser totalmente naturalizadas: meninos gostam de jogar futebol e as meninas gostam de pular corda. Na mesma direção, meninos são "mais agressivos" e as meninas são "mais meigas". Mas será que isso acontece sempre do mesmo modo e de uma maneira homogênea?

Mesmo sem ainda oferecer respostas a estas questões, não é difícil perceber que as diferenças acontecem tanto em momentos "oficiais" quanto naqueles "não oficiais" do contexto escolar. Se partirmos do pressuposto de que os espaços "não oficiais" (ou de dispersão) são também espaços pedagógicos, somos levados a considerar que o ambiente do recreio escolar se constitui um local de aprendizagem não oficial e não intencional. Mas o que se aprende

Movimento, Porto Alegre, v.12, n. 01, p. 59-80, janeiro/abril de 2006. 
nesses momentos? De que maneira isto acontece?

A busca de respostas a estas questões nos conduziram a procurar entender como gênero e sexualidade, ao atribuírem diferentes significados às práticas corporais, atravessam ou instituem modos diferenciados de ser menino e menina. Neste contexto, procuramos saber $o$ que e como se aprende a ser menino e menina no universo cultural do recreio e, também, pensar como o corpo se torna alvo de determinados discursos e como as práticas corporais vivenciadas no recreio disciplinam/resistem nos corpos ${ }^{1}$.

Estes objetivos nos levaram a observar o recreio escolar, durante um ano, e a problematizar o que ali se viu e registrou em forma de diário de campo, apoiando-nos na perspectiva dos Estudos Culturais e de Gênero que se aproximam do pós-estruturalismo de Michel Foucault ${ }^{1}$. Sobre isto, algumas considerações são necessárias, no sentido de localizar este referencial teóricometodológico num campo acadêmico científico particular.

\section{Pressupostos teóricos}

A seguir, apresentamos, sob a forma de pressupostos teóricos, os conceitos que foram importantes para a realização deste estudo. Cabe destacar que não há, aqui, a intenção de realizar uma revisão de cada um deles, nem de historicizá-los. Também não se pretende trabalhar com todas as suas possibilidades de operacionalização, mas indicar com que sentidos esses termos foram compreendidos e incorporados a esta pesquisa.

\footnotetext{
Para maiores detalhes sobre pós-estruturalismo e estudos Culturais, ver Marisa Vorraber Costa (2000); Alfredo Veiga-Neto (2000), Tomas Tadeu da Silva (2000b). Para ver as articulações entre pós-estruturalismo e feminismo, ver Guacira Lopes Louro (2001) e Dagmar Meyer (2000; 2001 e 2003). Ainda, esclareço que de acordo com as normas da ABNT, nas citações deve constar só o sobre nome do autor. Apesar disso, com vistas a identificar o gênero de quem escreve e diferenciar os/as diferentes autores/as, optei por citar nome e sobrenome cada vez que utilizar por primeira vez um/a autor/a.
}

Movimento, Porto Alegre, v.12, n. 01, p. 59-80, janeiro/abril de 2006. 
O primeiro pressuposto remete à importância da lingua$\mathrm{gem}^{2}$, entendendo-se que ela atribui sentido ao mundo e, dessa forma, constrói a realidade na qual vivemos e nos inserimos. Assim, os elementos de nossa vida social são conformados discursiva e lingüisticamente. A linguagem não só expressa as características dos elementos de sentido, mas também os constitui (STUART HALL,1997).

Outros aspectos da linguagem a serem considerados, nesta perspectiva, seriam sua "indeterminação, ambigüidade e instabilidade" (SILVA, 2000a, p. 91). Isso significa que ela não descreve a realidade, mas antes a constrói. É pelo caráter indeterminado, fragmentado, ambíguo e instável da linguagem que se torna possível desterritorializar sentidos que muitas vezes se busca fixar. Ou seja, é justamente a pressuposição de que a construção de sentidos homogêneos e fixos é uma impossibilidade que torna possível pensar os processos de significação como um campo de disputa permeado por relações de poder.

O segundo pressuposto aqui assumido envolve o conceito de representação, entendida como sistema de significação que permite dar sentido ao nosso mundo. Os sistemas de significação constroem lingüística e culturalmente os sentidos que são atribuídos aos modos de pensar e agir sobre as diversas dimensões da vida, incluindo a masculinidade e feminilidade (KATHRYN WOODWARD, 2000; SILVA, 2000a). Segundo Silva (1999, p. 32), a representação é entendida como "marca material, visível, palpável, do conhecimento [...] uma inscrição, marca, traço, significativo". Nesse sentido, ela se caracteriza por sua exterioridade e materialidade, isto é, ela se expressa "por meio de uma pintura, de uma fotografia, de um filme, de um texto, de uma expressão oral" (SILVA, 2000a, p. 90-91).

${ }^{2}$ A "virada lingüística" ficou conhecida como um processo em que foi possível observar a mudança do foco da construção social, deslocando-se dos atores e eventos para a linguagem. Foi quando a história passou a ser percebida como algo em que os sujeitos são constituídos através dos jogos de linguagem (VEIGA-NETO,1996).

Movimento, Porto Alegre, v.12, n. 01, p. 59-80, janeiro/abril de 2006. 
Essa forma de entender linguagem e representação, neste estudo, permitiu-nos considerar que a linguagem constitui nossas práticas discursivas e não-discursivas ${ }^{3}$ e que a representação as coloca em circulação, produzindo sentidos e construindo realidades (LOURO, 2001, p.65 e 98). Louro (2001, p. 99) entende que, nessa perspectiva, "não cabe perguntar se uma representação 'corresponde' ou não ao 'real', mas, ao invés disso, como as representações produzem sentidos, quais seus efeitos sobre os sujeitos, como elas constroem 'o real"'.

Desse modo, o mapeamento de práticas discursivas e nãodiscursivas constitutivas de determinados locais ou instituições (neste caso, o recreio escolar) possibilita tanto descrever e analisar a constituição de sujeitos femininos e masculinos, como também refletir criticamente sobre essa construção. Permite, ainda, a problematização daqueles significados atribuídos às práticas corporais e ao gênero que determinam ou favorecem formas particulares de ser e de agir que são socialmente hierarquizadas.

O terceiro pressuposto remete à ampliação dos modos de se entender educação: antes limitada à família e à escola, passa-se a entendê-la como algo que abrange não só os âmbitos escolares e familiares, como também os meios de comunicação, as artes, a música de diferentes tipos, a informática, os brinquedos, os filmes, as revistas, etc. Esses artefatos culturais ${ }^{4}$ atuam como modos de ensinar um jeito de ser (HALL, 1997). Isso permite-nos ampliar o entendimento dos espaços que são educativos, bem como das pedagogias e das aprendizagens, agora não nos limitando aos es-

\footnotetext{
${ }^{3}$ É necessário destacar que aquilo que Foucault definiu como práticas (discursivas ou não-discursivas) têm extensas implicações, e não pretendo discuti-las nesta problematização. Para mais detalhes, ver Rosa Maria Bueno Fischer (2001).

${ }^{4}$ Trabalhamos com a idéia dos brinquedos, filmes, músicas, etc. como artefatos culturais em que observamos uma cadeia de produção cultural. Segundo lole Trindade (2001, p.12), eles são importantes "na medida que não interessa o artefato em si mesmo, mas pelo sentido que recebem nas práticas culturais e ao constituir outras mais. Isto permite observar como determinadas músicas, filmes, etc., como artefatos que 'cristalizam' de alguma maneira significados e representações de determinadas épocas".
}

Movimento, Porto Alegre, v.12, n. 01, p. 59-80, janeiro/abril de 2006. 
paços determinados previamente e fixados formalmente para terem essas características. Assim, é possível entender o recreio como um espaço de aprendizagem social em que as características do contexto social não ficam de fora do contexto institucional.

O quarto pressuposto envolve a noção de cultura, concebida como um campo de constantes lutas, ações, contestações, aceitação e resistências em que os sujeitos se conformam em grupos diversos, com particularidades específicas. No contexto da cultura, os sujeitos in-corporam marcas/atributos de gênero, etnia, nacionalidade, geração e classe, por exemplo, e essas marcas são significadas e valoradas em sistemas de classificação que hierarquizam sujeitos e grupos sociais.

Além disso, os sujeitos vivem em espaços histórica e socialmente diferenciados que também promovem maneiras diferentes de ser. Assim, a cultura inscreve particularidades nos sujeitos (SILVA, 1999). Ela não só conforma os contextos sociais e os diferentes sujeitos que os integram, como também conforma modos de ser e de agir em diferentes estágios da vida de um mesmo sujeito. Nessa direção e com esse entendimento, é possível, então, observar diferentes modos de viver e de sentir a feminilidade e a masculinidade em diferentes tempos e espaços culturais (MEYER, 2003).

Um desdobramento importante deste quarto pressuposto importante é o de "cultura escolar", a qual é entendida como um conjunto de características que inclui "práticas, condutas, modos de vida, hábitos e ritos" que ocorrem na escola (Antonio Viñao Frago, 1995, p. 68), mas envolvendo indivíduo advindos de diferentes universos sociais e culturais. Assume-se que a escola constitui um sistema educativo, curricular e pedagógico, mas também um espaço social e cultural no qual as relações entre as pessoas adquirem particular importância, pelo convívio e pelos contínuos intercâmbios de idéias, de conceitos, de afetos e de saberes. É por esta razão que não se pode considerar a cultura escolar como estando circunscrita aos limites geográficos do espaço escolar e

Movimento, Porto Alegre, v.12, n. 01, p. 59-80, janeiro/abril de 2006. 
de forma independente de uma cultura social mais ampla.

É no contexto dessa cultura escolar, informada pelas culturas constitutivas dos diferentes sujeitos que a integram, que o recreio identificado como um tempo/espaço onde ocorrem interações entre diferentes tipos de estudantes, que seriam supostamente mais livres e menos regradas pelos dispositivos escolares - se constitui um momento da vida escolar em que acontecem diferentes aprendizagens, em especial aquelas que ocorrem através das brincadeiras.

Com base nestes pressupostos e com a intenção de estudar no recreio e não o recreio, perguntamos: quais são os significados sociais atribuídos ao corpo e ao gênero nas práticas corporais (brincadeiras) que permeiam o recreio da primeira à quarta série de uma escola pública de Porto Alegre? Como estas práticas corporais vivenciadas no recreio disciplinam corpos de meninos e meninas? Que significados meninas e meninos conferem, concedem ou assumem em relação a essas aprendizagens? Como o corpo torna-se alvo de determinados discursos que evidenciam algumas representações em detrimento de outras?

$\mathrm{Na}$ busca destas respostas realizamos este estudo através de uma metodologia de inspiração etnográfica ${ }^{5}$, observando os recreios de uma escola pública, procurando problematizar a heterogeneidade própria desse espaço, identificando os diferentes discursos e práticas que evidenciam algumas representações em detrimentos de outras, particularmente em relação às questões de gênero mapeadas no universo das brincadeiras. Mesmo entendendo que as brincadeiras que se realizam no recreio são tradicional-

\footnotetext{
${ }^{5}$ Com um ano de presença no campo, acompanhamos diferentes momentos da rotina escolar (ingresso, egresso, sala de aula, passeios, lanche, festas e o recreio), assim como atividades fora da escola, como a participação em alguns aniversários. Produzimos as informações através de procedimentos como observação direta, observação participante (Becker, 1997; Daniela Knauth et. al., 2000), "bola de neve" (S. J. Taylor, 1996), conversas informais com diferentes pessoas da comunidade e através de entrevistas com 58 crianças (Albarello Luc, 1997; R. G. Burgess, 1997; S. Becker, 1997; Tânia Cruz, 2004; Martine Delfos 2001; Zélia Fabri, 2002).
}

Movimento, Porto Alegre, v.12, n. 01, p. 59-80, janeiro/abril de 2006. 
mente consideradas espontâneas, buscamos analisá-las na sua dimensão educativa, considerando que elas carregam significados que as crianças podem produzir e atribuir a partir do meio social no qual se encontram.

A escolha do estudo de inspiração etnográfica possibilitou uma análise por dentro, na tentativa de tornar "o familiar em estranho", ou seja, observar o dia-a-dia, aquilo que percebemos como natural de nossa sociedade, procurando entender e discutir como se constroem e se desenvolvem práticas cultuais que a um primeiro olhar costumamos considerar como parte de nossa natureza (STIGGER, 2002).

\section{Recreio: lugar de aprendizagens "de gênero" \\ O gênero no espaço do recreio}

As aprendizagens de gênero aqui focalizadas acontecem tanto no espaço amplo do recreio quanto nas brincadeiras específicas que ali são vivenciadas. O recreio escolar desenvolvese no pátio da escola, ocupado, na sua grande maioria, só pelas crianças. É um momento que acontece todos os dias, dentro da rotina escolar e com inumeráveis regras, nem sempre explícitas - embora a sua forma de funcionamento seja conhecida por todos que nele estão inseridos. Nesse sentido, o recreio desenvolve-se com particularidades diferentes em cada instituição e vai se complexificando, caracterizando um espaço particular, com suas próprias regras e negociações, criando sua própria cultura. A cultura do recreio poderia ser denominada de cultura oral do recreio. O ingresso nessa cultura "requer aprender um conjunto de regras e rituais [...] que podem ser diferentes para meninas e meninos" (GRUGEON, 1995, p. 24). Essa cultura pode ser considerada oral porque constitui uma cultura própria das crianças e do espaço do recreio, mas ela não se limita só a um vocabulário oral, englobando também gestos, atitudes, significados, etc.

Movimento, Porto Alegre, v.12, n. 01, p. 59-80, janeiro/abril de 2006. 
A cultura do recreio vai criando suas próprias regras, o que permite passar de uma experiência distante para uma experiência próxima que os membros de uma cultura específica utilizam para compreender seu próprio contexto (CLIFFORD GEERTZ, 1999). Cria-se uma cultura particular dentro do contexto escolar e do recreio com algumas características próprias, como, por exemplo, uma negociação que inclui a maneira de lidar com os espaços conforme gênero e geração.

Nesse sentido, podemos descrever algumas situações. Estávamos observando crianças de primeira a quarta série, e havia dois grupos. Um deles, de meninas da primeira série, estava brincando numa quadra de vôlei; na outra quadra de vôlei, meninos de uma segunda série jogavam futebol. Num determinado momento, adolescentes que tinham um horário vago passaram a ocupar esses espaços.

A ocupação de espaços, no recreio, era muito diferenciada pela idade e pelo gênero. $\mathrm{O}$ grupo de meninas que estava brincando era de primeira série. Quando apareceram as garotas maiores com uma bola de vôlei querendo ocupar o espaço, perceberam que as meninas menores estavam na quadra. Uma das adolescentes aproximou-se e perguntou: "vocês poderiam brincar atrás da quadra? Assim, a gente joga bola". As meninas menores concordaram e, imediatamente, foram para trás da quadra e continuaram brincando, liberando pacificamente o espaço para as adolescentes.

As meninas pequenas fizeram isso sem reclamar e não pareceram ficar chateadas, pois tinham ainda um espaço para brincar. Não houve uma situação visível de imposição - elas tinham a opção de ficar no espaço, mas havia menos meninas do que adolescentes justificando-se, assim, a troca de lugar.

No caso dos meninos, foi diferente. O grupo de adolescentes começou a chegar na quadra e foi ocupando o espaço. Em nenhum momento os adolescentes perguntaram alguma coisa ou se dirigiram aos meninos menores, já que muito deles saíram imediata-

Movimento, Porto Alegre, v.12, n. 01, p. 59-80, janeiro/abril de 2006. 
mente do lugar. Mas um deles não gostou da invasão. Começou aí uma ameaça corporal para que o menor se mantivesse fora da quadra. Então, o menino menor ficou pisando na linha e olhando para os adolescentes. Um deles veio e ficou bem pertinho do pequeno, ameaçando-o, para que saísse. Cabe destacar que, nesse suposto "diálogo", não foi dita nenhuma palavra. Quando o menino menor viu-se superado em tamanho pelo adolescente, desistiu de ficar na quadra e voltou a jogar futebol na lateral, junto com seus colegas. Posteriormente, quando realizamos as entrevistas, confirmamos isso - os adolescentes dirigem-se aos meninos menores falando: "o meu, vão saindo" (03/11/04).

Aqui, nesses exemplos, podemos observar diferentes maneiras de se movimentar no espaço do recreio, segundo o gênero. As meninas foram mais tranqüilas e conversadoras ou se submeteram mais facilmente, e os meninos mostraram-se mais violentos e agressivos. Isso converge com aquilo que comumente é falado sobre o gênero: "meninas são mais submissas, e meninos são mais violentos", como se essas características fossem intrínsecas aos gêneros. Mas nem sempre os meninos são mais agressivos e as meninas, mais submissas. Em alguns casos, são as meninas que procuram mais briga, como durante a brincadeira do pega-pega, quando ficam chutando ou batendo nos meninos ou, ao serem pegas por um menino, ficam batendo nele até serem liberadas.

Em outras situações, a negociação, a conversação e o diálogo entre os grupos são totalmente dispensados, como aconteceu no exemplo que relato a seguir. As meninas da primeira série ficavam sempre brincando atrás da quadra de vôlei, que constitui um canto no pátio. Perguntados por que ficavam brincando sempre no mesmo lugar, tendo todo o pátio à sua disposição, responderam, sem hesitar: "porque aqui ninguém nos atrapalha!" (D. de C. 21/10/04).

Comportamentos generificados no espaço escolar já foram observados e descritos, também, em outros trabalhos. Por exemplo, segundo Carlos Neto (1997, p. 17), as crianças de 8 a 12

Movimento, Porto Alegre, v.12, n. 01, p. 59-80, janeiro/abril de 2006. 
anos preferiam, por ordem de importância, os espaços esportivos, depois as zonas de jogo livre, as zonas verdes e os espaços de aventura e finalmente as áreas de descanso. Isso depende, também, das condições de infra-estrutura da instituição. No caso da escola pesquisada, o pátio se dividia em quadras esportivas, com algumas zonas de descanso demarcadas pelos bancos. Então, é de se esperar que, com tão poucas opções, os primeiros espaços a serem ocupados sejam as quadras esportivas e pelos adolescentes, que se impõem pelo tamanho corporal e pela idade. Identificamos essa divisão dos espaços como classificações dos/as próprios/as alunos/as, pois, na escola que pesquisamos, não estava entendida essa divisão "oficialmente", mas os/as alunos/as sabiam para onde se dirigir se queriam descansar, brincar de bola ou realizar outra atividade.

Barrie Thorne (1993) estudou o pátio de escolas norte-americanas e observou que meninos ocupavam dez vezes mais espaços do que meninas, principalmente os espaços esportivos. Em relação a esse aspecto, Elisabeth Grugeon (1995) entende que, com um simples olhar no pátio do recreio, é possível observar agrupamentos de meninas que denotam certa intimidade e meninos correndo de um lado para o outro. Isso também pôde ser observado na escola pesquisada, onde os meninos ocupam mais as quadras esportivas; quando não ocupam as quadras, utilizam mais os espaços, seja correndo, seja dando grandes chutes na bola de um canto ao outro do pátio. Enquanto isso, as meninas aparentam uma maior intimidade, pois ficam em grupos menores e de maneira mais sedentária, sentadas ou em pé, mas sempre conversando. Helena Altmann (1998, p. 26) refere que "o esporte é um meio de os meninos exercerem domínio de espaço da escola", destacando que as meninas resistem a essa dominação brincando de jogos não-esportivos e não jogando futebol.

Nos exemplos relatados neste tópico, as resistências/dominações/negociações são passíveis de serem observadas em situações em que, às diferenças de gênero, se agregam a idade, a força

Movimento, Porto Alegre, v.12, n. 01, p. 59-80, janeiro/abril de 2006. 
e/ou a habilidade técnica. Segundo as idéias de Altmann (1998, p. 56), "gênero, idade, força e habilidade (...) formavam um emaranhado de exclusões vividos em aulas e recreios".

\section{O gênero nas brincadeiras: ...}

A seguir, descrevemos algumas situações observadas em brincadeiras vivenciadas pelas crianças, no dia-a-dia da escola. Em uma delas, que envolve meninos e meninas da mesma idade (segunda série), alguns meninos e uma menina estavam jogando futebol. Num momento ela errou uma jogada e acabou saindo do jogo. Em uma conversa, ela contou-me: "falaram que eu não sabia jogar, por isso, eu saî". E ainda disse: "Olha lá, eles estão jogando futebol e não deixam ninguém jogar com eles"; apesar de serem só quatro meninos em toda a quadra "não deixavam ninguém mais jogar" (D. de C. 8/12/03).

A partir desse diálogo, algumas questões podem ser formuladas. Será que isso acontece porque ela é menina? Será que aconteceria o mesmo se fosse um menino? Quem autoriza essa apropriação do espaço? Como respostas a essas questões, poderíamos considerar que, apesar de a menina não saber exatamente o motivo pelo qual ela não pode jogar, ela aprendeu uma regra que não permitia negociação. Essa regra não está explícita em lugar algum. Ela não só não pode jogar futebol, como não pode jogar com os meninos nem pisar na quadra para brincar de outra coisa porque os meninos se apropriam e legitimam esse espaço como sendo próprio para um jogo masculino.

Conforme já foi observado nos trabalhos de Altmann (1998) e Vinicius Gonçalves (2004), os meninos, através da habilidade técnica do saber jogar futebol, impõem-se no espaço (a quadra) e também no tempo do recreio, supostamente um espaço de liberdade para todas as crianças brincarem. Destacamos, entretanto, que as meninas não são vítimas passivas dessa ordem - dependendo do tipo de jogo, em certos momentos, elas a subvertem. No exem-

Movimento, Porto Alegre, v.12, n. 01, p. 59-80, janeiro/abril de 2006. 
plo citado, provavelmente pelo fato de o futebol no Brasil ser um jogo tradicionalmente masculino, Ana parece ter sido excluída tanto pelo fato de ser menina quanto pela sua menor habilidade técnica. Em algumas outras situações, no entanto, as meninas têm uma habilidade técnica, mas os meninos não têm interesse em jogar com elas, como acontece nas observações realizadas por Altmann (1998).

Essa situação empírica mostra como as habilidades e características de meninos e de meninas não são parte de um processo entendido comumente como natural ou biológico, como também são constituídas por aprendizagens próprias de cada contexto histórico e social. Tais processos de aprendizagem também configuram o recreio escolar como um espaço em que as vivências quotidianas e os sentidos atribuídos a elas, fazem diferença e marcam os corpos para distingui-los, pois definem como se pode ser, o que se deve ou não fazer, de que modos e em que lugar, caracterizando os corpos e gestos de uma maneira em detrimento de outras. Dessa forma, a escola delimita os espaços, separa e institui o que cada um pode e não pode fazer ela "informa o 'lugar' dos pequenos e dos grandes, dos meninos e das meninas" (LOURO, 2001 p.58).

Outros atravessamentos de gênero podem ser dimensionados no esporte e, especificamente no futebol. Relatamos três situações diferentes. A primeira envolve um menino que não inclui o futebol em seus interesses de brincadeiras e, por isso, é considerado como "bicha" pelos colegas. A segunda envolve outro menino que joga futebol mas que também pratica balé; entretanto, ninguém o incomoda pois "ele faz o que um menino deveria fazer".

Uma terceira situação diz respeito a Aline, uma menina que joga futebol com os meninos. Meninas que jogam futebol, como esta aqui focalizada, têm técnica ou uma habilidade motriz que possibilita uma integração, ou seja, elas são "boas de bola”. Isso já foi observado no trabalho de Altmann (1998), mostrando que a habilidade motora parece atuar como um mecanismo de exclusão e inclusão nos esportes. Além disso, essas meninas não necessari-

Movimento, Porto Alegre, v.12, n. 01, p. 59-80, janeiro/abril de 2006. 
amente deixam de gostar ou de brincar com outras meninas. Mônica, ao referir-se a uma outra menina que joga futebol, disse: "ninguém fala nada para ela, nadinha”.

Mas será que Aline é incomodada por jogar futebol com os meninos? O que as outras meninas pensam sobre ela? Nesse caso, perguntamos a Aline se alguém implicava por ela sempre jogar futebol com os meninos, e ela respondeu que não. A maioria das crianças reconhece que não implica com ela, mas, segundo Brenda, "às vezes os meninos pegam no pé dela, que ela é meio menino [...] que ela tem jeito de menino, até a voz dela, falam de 'menino', ela quer jogar bola e nunca vai brincar com as meninas de pular corda".

Essas falas reafirmam o que vinha sendo discutido: que o comportamento considerado natural é que meninos brinquem de futebol e as meninas não. Se alguma delas tenta resistir a essas normas, a própria brincadeira as captura de outro modo, ao classificá-las como "menino" ou com outras nomeações. Isso, de certo modo, reitera a hegemonia da heterossexualidade e a dicotomia tradicional homem-mulher.

Em relação à dança, meninas ficam dançando, em grupos, e realizando coreografias de moda; ao observá-las, alguns meninos começam a mostrar-se interessados nessa atividade, até que aparece um colega e implica com eles. Imediatamente, os meninos que estavam interessados parecem já não estar mais. Nesse sentido quando realizamos as entrevistas, muitos dos meninos afirmaram que "o recreio era legal com música", pois "era legal ver as meninas dançarem", mas não admitiam que eles também dançavam.

E o que fazem os meninos enquanto as meninas dançam? No começo das observações, ficamos pensando que as meninas estavam muito mais expostas (e elas estão) do que os meninos, já que eles simplesmente não participavam. Mas é possível dizer, também, que tanto as meninas quantos os meninos estão sob uma forte regulação de sua conduta neste caso. Os meninos constituem um grupo não tão exposto, mas nem por isso não-regulado. Eles cons-

Movimento, Porto Alegre, v.12, n. 01, p. 59-80, janeiro/abril de 2006. 
tituem um "silêncio" e precisam se ajustar a um modelo de masculinidade que é preciso reforçar o tempo todo; qualquer "escorregada" pode ser motivo suficiente para gozação.

Então, enquanto as meninas dançavam, muitos meninos da mesma idade ficavam em volta, não só observando, mas dançando também; porém, disfarçavam o movimento ou o exageravam; fazendo de conta que não o faziam, realizavam parte dos movimentos ou incluíam gestos que ridicularizavam a execução. Outros meninos estavam jogando outra coisa e, de repente, movimentavam-se no mesmo ritmo que as meninas; ou estavam sentados e depois sabiam todos os passos, etc. Enfim, faziam qualquer coisa que não permitisse afirmar que estavam realizando o movimento "tal como as meninas".

\section{Algumas considerações finais}

A escola configura diferentes espaços e tempos em suas salas de aula, nos pátios e nos deslocamentos das crianças. Observa-se, ainda, que a escola não é um espaço só das crianças, mas comporta um espaço onde ou através do qual se faz aquilo que pode ser feito, havendo também um espaço para as fugas e resistências por parte das crianças. Nesse sentido, a escola não constitui um lugar homogêneo e de paz absoluta. Ela é uma instituição onde se discutem, se aceitam, se rejeitam e se impõem significados através de processos em que as crianças se encontram inseridas participando de negociações culturais ou imposições tanto ou mais complexas e até tão disciplinadoras quanto os processos de que participam os adultos. Nesse contexto, cada espaço da instituição - as salas de aula, a sala de professores, a cozinha, o saguão, o corredor ou o pátio - tem características comuns e, também, particularidades que lhe são próprias, configurando sua própria cultura.

Comumente, a instituição exerce um controle sobre as crianças, ditando por onde elas podem ou não circular. Esse controle estende-se até o recreio. Nesses espaços (tanto escola quanto re-

Movimento, Porto Alegre, v.12, n. 01, p. 59-80, janeiro/abril de 2006. 
creio), as crianças "não são tão livres" quanto poderíamos acreditar a partir de um olhar à distância. As crianças não brincam todas juntas, não fazem sempre o que querem, nem todas brincam em todos os espaços e, ainda, nem todas brincam do que gostariam.

É preciso dizer, ainda, que estas práticas e este espaço escolar, tradicionalmente entendidos como de dispersão e lazer, têm sido consideradas um "tema menor" de pesquisa no campo da Educação Física e, ainda, como "vida entre parênteses" ou um "saco vazio" onde atividades "livres" são inseridas para "passar o tempo", sem nenhuma intencionalidade. Supõe-se que esses momentos se caracterizariam por não ter nenhuma dimensão educativa, sobretudo, em relação ao gênero, como se "nascêssemos" possuidores de um determinado gênero, não existindo nada que construa/ reforce/permeie as aprendizagens. E esse é um pressuposto que a análise das observações realizadas permitiu desnaturalizar quando as descrevemos como aprendizagens não-oficiais e não-intencionais que não necessariamente integram, de forma explícita, os objetivos curriculares da instituição, mas que a permeiam e constituem. Foi possível entender que esse espaço produz e veicula significações, segundo as pessoas que dele participam, sejam crianças, funcionários/as ou professores/as, salientando-se que, dentro desses grupos, nem todos/as vêem o recreio da mesma maneira. O recreio é vivenciado por diferentes pessoas, e cada uma delas outorga a esse momento um significado diferente.

Além disso, foi possível dimensionar que, dentro desse aparente caos que constitui esse momento, existe uma ordem, ou seja, o recreio tem sua própria rotina que estabelece o que as crianças fazem e não fazem, do que brincam, com quem e em que espaços. $\mathrm{O}$ recreio constitui um momento que parece ser um caos, mas pode-se observar nele certas regras e práticas normativas. Dessa forma, o espaço/tempo do recreio cria e recria sua própria cultura, uma cultura complexa que funciona segundo regras próprias e específicas. Acontecem no recreio diferentes imposições e/ou negociações, segundo o gênero e a idade. Assim, é possível dizer 
que esse espaço não é um espaço de liberdade e de espontaneidade como poderia parecer num primeiro momento, pois existe uma certa imposição/negociação do que pode ser feito, em que parte do pátio e com quais crianças. Meninos e meninas conformam grupos, deslocam-se, fazem coisas diferentes, circulam, etc. Nesse espaço, então, acontecem aprendizagens. No que se refere a gênero, as crianças aprendem algumas formas de agir e de comportar-se como meninos e meninas de determinados tipos.

Conforma-se, também, uma ocupação dos espaços segundo o gênero e a idade - diferentes grupos ocupam determinados espaços. Os meninos ocupam geralmente mais espaço do que as meninas, situação que se repete entreos/as adolescentes. Essa ocupação, entretanto, não é fixa; existem negociações, conflitos e reapropriação dos espaços. Os grupos acabam configurando um mapa ou uma "geografia dos gêneros" em que, em diferentes partes do pátio, acontecem diferentes brincadeiras, segundo o gênero e a idade. Há brincadeiras tradicionais e esperadas, como um esporte na quadra esportiva, mas também realizam-se algumas brincadeiras não esperadas ou permitidas em lugares inusitados.

No contexto da escola estudada, meninos adolescentes ocupam mais as quadras esportivas do que as adolescentes. Estas ficam em espaços menores ou praticam o vôlei. Meninos brincam geralmente de futebol ou luta; meninas brincam mais de pular corda, elástico ou pega-pega. Também os meninos de primeira a quarta série ocupam mais espaços do que as meninas. As meninas da quarta série, por sua vez, ocupam mais espaços do que as meninas da primeira série. Dessa forma, vemos que existe uma negociação/imposição dos espaços segundo uma hierarquia presente.

O esporte funciona como uma estratégia de legitimação da masculinidade para os meninos, que assim ocupam a maior parte do pátio. É um espaço em que meninas não brincam devido à articulação de dois elementos: por serem meninas e por serem menos habilidosas. Isso também se aplica àqueles meninos consi-

Movimento, Porto Alegre, v.12, n. 01, p. 59-80, janeiro/abril de 2006. 
derados menos habilidosos e fortes, estabelecendo-se aí um parâmetro de valoração da "masculinidade".

Isso leva-nos a considerar que as brincadeiras - que parecem ter só um caráter prazeroso - têm também uma dimensão produtiva; elas disciplinam os sujeitos de forma distinta, para viverem dentro de um contexto social e histórico que valoriza alguns jeitos de ser menino e de ser menina; jeitos estes que são demarcados por padrões que os grupos culturais que eles integram consideram como normais. Nessa perspectiva, o gênero produz e é produzido, também, através das brincadeiras. A diferença se constrói como uma lógica estabelecida a priori, a partir da qual, ou através da qual, as crianças aprendem a justificar a segregação.

\footnotetext{
THE GENDER'S CONSTRUCTION IN THE SCHOOL PLACE

ABSTRACT: We look for, from the lines of the Cultural and Gender Studies that approach the poststructuralism of Foulcault, to understand how the gender and the sexuality establish different ways of being boys/ girls inside the break time play. Considering that these actions take place through relations of power, we look for sought to map and identify them through an ethnographically inspired methodology. We focused on groups of $2^{\text {nd }}$ and $3^{\text {rd }}$ grades. We argue that, in the space of break time a non-official and non-intentional learning takes place, from which or through which the children learn how to be boys and girls.

Key words: Studies of Gender. Break time. Ethnographically. Children's play.
} 


LA CONSTRUCCIÓN DEL GÊNERO EN EL
ESPACIO ESCOLAR
Resumen: Procuramos, a partir de las vertientes
de los Estudios Culturales y de Género que se
aproximan del pós-estructuralismo de Foucault,
entender como el género instituye modos diferen-
ciados de ser niño/a en el recreo escolar. Consi-
derando que ese es un proceso permiado de rela-
ciones de poder, procuramos mapearlas e
identificarlas a travéz de una metodología de
inspiración etnográfica. (observación participante
y entrevistas) realizada, durante un ano, en una
escuela pública de Porto Alegre, RS. Focalizamos
un segundo y un tercer grado. Argumentamos que,
a través de los juegos, sucede un aprendizaje no-
oficial y no-intencional, a partir del cual los/las niños/
as apre(e)enden determinadas formas de
femenilidad e de masculinidad.
Palabras-clave: Estudios de género. Recreo.
Etnografia. Juegos.

\section{REFERÊNCIAS}

ALBARELLO, Luc. et. al. Práticas e Métodos de Investigação em Ciências Sociais. Portugal: Gradiva, 1997.

ALTMANN, Helena. Rompendo Fronteiras de Gênero: Marias (e) Homens na Educação Física. Dissertação (Mestrado). Programa de Pós-Graduação em Educação. Faculdade de Educação da Universidade Federal de Minas Gerais. 1998.

BECKER, S. Howard. Métodos de Pesquisa em Ciências Sociais. São Paulo: HICITEC. 1997.

BOGDAN, Robert.; KNOP, Sari B. Investigação Qualitativa em Educação. Uma Introdução à teoria e aos métodos. Porto: Porto, 1994

BURGUESS, R.G. A Pesquisa de terreno- uma introdução. Porto: Celta, 1997.

COSTA VORRABER, Marisa. Estudos Culturais: para além das fronteiras disciplinares. In: COSTA VORRABER, Marisa (Org.). Estudos Culturais em Educação. Porto Alegre: UFRGS, 2000.

Movimento, Porto Alegre, v.12, n. 01, p. 59-80, janeiro/abril de 2006. 
CRUZ, Tania. Meninas e Meninos no Recreio: Gênero, sociabilidade e Conflito. Tese (Doutorado). Faculdade de Educação. São Paulo. 2004.

DELFOS, Martine. F. Me escuchas? Como conversar com niños de cuatro a doce años. Bernard Van Leer Foundation. 2001.

FABRI DERMATINI, Zelia. B. Infância, Pesquisa e Relatos Orais. In: GOULAT, Ana Lúcia;FABRI DERMATINI, Zelia. B.; PRADO, D. Patrícia. (Orgs.), Por uma Cultura da Infância: metodologias de pesquisa com crianças. Campinas, SP: Autores Associados, 2002.

GEERTZ, Clifford. Do Ponto de vista dos nativos: a natureza do entendimento antropológico. In: O Saber Local: novos Ensaios em antropologia interpretativa. Tradução: Mello Joscelyne, Vera. 2.ed. Petrópolis: Vozes, 1999.

GONÇALVES, Vinicius Pauletti. A Quadra e Os Cantos: a arquitetura dos Gêneros nas Práticas corporais escolares. GTT04: Educação Física e Escola. Primeiro congresso sulbrasileiro. 2004. (Texto completo em cd-rom).

GRUGEON, Elizabeth. Implicaciones de Género en la cultura del patio del recreo In: WOODS, Peter e HAMMERSLEY, Martyn (Orgs.). Género, Cultura y Etnia en la Escuela: Informes Etnográficos. Paidós: Ministerio de Educación y Ciencia. España, 1995.

FISCHER, Rosa Maria Bueno. Foucault e a análise do discurso em educação. Cadernos de Pesquisa, São Paulo, n. 114. nov. 2001. p.197-223.

FOUCAULT, Michel. Vigiar e Punir.Vozes: Petrópolis. 2002a.

Microfísica do Poder. Rio de Janeiro: Graal, 2002b.

HALL, Stuart. A Centralidade da Cultura: notas sobre as revoluções culturais de nosso tempo. Educação \& Realidade, Porto Alegre. v. 22, n. 2, p. 15-46, 1997.

KNAUTH, Daniela; CERES, Vítoria; AGRA HASSEN, Maria. Pesquisa Qualitativa em Saúde. Porto Alegre: TOMO, 2000.

LOURO, Guacira Lopes. Gênero, Sexualidade e Educação: Uma Perspectiva Pós-Estruturalista. 4.ed. Petrópolis: Vozes, 2001.

MEYER, Dagmar. Cultura e Docência teuto-brasileiro-evangélica no Rio Grande do Sul. Santa Cruz do Sul. São Leopoldo: Sinodal, 2000.

A arquitetura de um regime de representação cultural: a escola elementar teuto-brasileiro-evangélica no rio grande do sul (1909-1939). REDES Revista do Mestrado em Desenvolvimento Regional UNISC. Estudos sobre imigração alemã. V.6. número especial. Santa Cruz do Sul. Maio 2001. p.53-73.

Movimento, Porto Alegre, v.12, n. 01, p. 59-80, janeiro/abril de 2006. 
Gênero e Educação: teoria e política. In: Louro, Guacira.; Neckel, Jane F; Goellner, Silvana Vilodre (Orgs). Corpo, gênero e sexualidade: um debate contemporâneo na Educação. Petrópolis: Vozes, 2003.

NETO, Carlos. Jogo \& Desenvolvimento da Criança. Lisboa: Faculdade de Motricidade Humana, 1997.

SILVA, Tomas Tadeu da. 0 currículo como fetiche - a política e a poética do texto curricular. Belo Horizonte: Autêntica, 1999.

. A produção social da identidade e da diferença. In: SILVA (org.) Identidade e diferença. A perspectiva dos Estudos Culturais. Petrópolis: Vozes, 2000a.

Documentos de Identidade: uma introdução às teorias do Currículo. 2da edição. Belo Horizonte. Autêntica. 2000b.

STIGGER, Marco Paulo. Esporte, Lazer e Estilos de Vida: um estudo etnográfico. Campinas, SP: Autores Associados. São Paulo (Coleção educação física e esportes), 2002.

TAYLOR, S. J. Y BOGDAN, R. Introducción a los Métodos Cualitativos de Investigación: La búsqueda de significados. Barcelona: Paidós. 1996.

THORNE, Barrie. Gender Play: girls and boys in school. Rutgers University. United States.1997.

TRINDADE, Iole Maria Faviero. A Invenção de uma nova ordem para as cartilhas: ser maternal e mestra. Queres ler? Tese (Doutorado). Programa de Pós-Graduação em Educação, Universidade Federal do Rio Grande do Sul. Porto Alegre. 2001

VEIGA-NETO, Alfredo. A Ordem das Disciplinas. Tese (Doutorado). Programa de Pós-Graduação em Educação, Universidade Federal do Rio Grande do Sul. Porto Alegre. 1996.

Michel Foucault e os Estudos Culturais. In: VORRABER COSTA, Marisa (Org.). Estudos Culturais em Educação. Porto Alegre, UFGRS, 2000.

VIÑAO FRAGO, Antonio. A Historia de la Educación e historia Cultural posibilidades, problemas, cuestiones. Revista Brasileira de Educação. ANPED (Associação Nacional de Pós-graduação e pesquisa em educação). Set/out/nov/ dez. n. 0. Brasilia.1995.

WORTMANN CASTAGNA, Maria Lúcia. Análises Culturais- um modo de lidar com histórias que interessam à educação In: VORRABER COSTA, Marisa (Org.) Caminhos Investigativos II: outros modos de pensar e fazer pesquisa em educação. Rio de Janeiro: DP\&A, 2002.

Movimento, Porto Alegre, v.12, n. 01, p. 59-80, janeiro/abril de 2006. 
WOODWARD, Kathryn. Identidade e diferença: uma introdução conceitual. In: SILVA, T. T. (Org.) Identidade e diferença: a perspectiva dos Estudos Culturais. Petrópolis: Vozes, 2000.

Recebido em: 30/11/2005 Aprovado em: 25/04/2006

Ileana Wenetz ilewenetz@gmail.com

Marco Paulo Stigger Universidade Federal do Rio Grande do Sul Escola de Educação Física Rua Felizardo, 750 - Jardim Botânico 90690-200 - Porto Alegre - RS stigger@adurfgs.ufrgs.br

Movimento, Porto Alegre, v.12, n. 01, p. 59-80, janeiro/abril de 2006. 